\title{
Is Evidence-Based Medicine Appropriate in Primary Care?
}

\section{Tamer Edirne*}

Department of Family Medicine, Medical School, University of Pamukkale, Denizli, Turkiye

A new paradigm was introduced three decades ago to the practice of medicine, suggesting using the best available evidence to make decisions about health care. Since then, Evidence-Based Medicine (EBM) has developed remarkably and physicians' attitude towards it is generally positive. Evidence-based decision making has gained popularity especially in primary care. A definition made by Dave Sackett which was published in the British Medical Journal in 1996 is: 'Evidence based medicine is the conscientious, judicious and explicit use of current best evidence in making decisions about the care of individual patients" [1]. No one can disagree that many people owe their lives to the precise science of EBM that was built on these foundations. Following these initiatives a supportive comment was made by Greenhalgh and Donald [2] who suggest EBM as a tool for quality improvement in primary care and define EBM as 'the use of mathematical estimates of the chance of benefit and the risk of harm, derived from high-quality research on population samples, to inform clinical decision-making' [2]. This approach forces primary care physicians to be knowledgeable, efficient and comprehensive while delivering evidence-based medical care. Incorporating evidence-based medicine into practice requires training in the skills of finding and applying good evidence to patients. Primary care practitioners must make clinical decisions each day but reliable evidence is not always available. Therefore, physicians' experience and judgment must complement and supplement their knowledge of published research studies. This presents a difficult challenge to the practitioner that deepens when combined with the never ending new knowledge of medical information, with patients' and physicians' uneasiness, with clinical uncertainty, and with new external pressures to standardize care. In addition, because finding evidence to answer clinical questions is essential to the practice of evidence-based medicine, it is required that the results of research to be collected in a systematic manner and made accessible to manage problems by reference to valid and relevant information. In Turkey, the proportion of family medicine specialists (family physicians) in primary care services is small compared with general physicians (medical school graduates). According to the study by Kahveci and Meads [3], the main barrier to practicing EBM was lack of training and Attitudes toward EBM differed significantly between primary care physicians and general physicians working in primary care in Turkey, which the authors believe results in variation in medical provision [3]. Similar findings are reported from Jordan, where $80.7 \%$ of family doctors welcomed promotion of EBM but only $56.1 \%$ reported that they ever used EBM in the practice [4]. Primary health care physicians in Saudi Arabia show a low level of awareness of extracting journals, review publications and databases, and even if aware, many did not use them. Only $16 \%$ had access to bibliographic databases and $10 \%$ to the worldwide web. The respondents showed a partial understanding of the technical terms used in EBM [5]. Shuval et al. from Israel share the information that especially general practitioners and doctors without previous EBM training are also in need for enhancing practical EBM skills [6]. On the other side, educators in medicine are not equipped or motivated to incorporate EBM into their clinical teaching. Beasley and Woolley suggest that faculty development programs for community faculty should feature how to use and teach basic EBM concepts to medical students [7]. In addition to known barriers, practicing EBM in primary care is thought to be problematic because of concerns about whether evidence exists to answer specific questions. Davies concludes that although the guidelines are useful resources for primary care clinicians, they only answer to two-fifths of questions used in their study [8]. In the UK, EBM has influenced the development of guidelines and quality standards for clinical practice over the last few years. In their paper, Slowther et al. inform us that there are, however, concerns among primary care clinicians that EBM is not always relevant to primary care and that excessive emphasis placed on it can lead to conflicts with a clinician's duty of care and respect for patient autonomy [9]. There are many forms of evidence that inform our practice, including Systematic Reviews (SRs), Randomized Controlled Trials (RCTs), strong observational studies and guidelines. Vause argues that guidelines synthesize all the evidence and help shift practice and points to changes in practice in response to evidence as leading to the recent reduction in cardiovascular deaths [10]. On the other hand, Mangin points that guidelines are a very imprecise tool, often including evidence that is poor quality or irrelevant and overly prescriptive for the complex contexts of primary care, while clinical decisions need to take into account many more factors than the ones presented in a linear flowchart [11]. A suggestion by Parsonson differs in that we should consider findings from alternative methodologies as well as large-sample double-blinded RCTs as evidence to inform our practice because original research conducted with single-samples to evaluate individual or small group responses to an intervention in our own primary care environment can add to our evidence base [12]. More than often, we will experience difficulties in finding relevant evidence to a specific patient with particular set of conditions, beliefs, expectations and social situation. According to Goodyear-Smith, we must also bring our professional experience and expertise into play and primary care will always be a science as well an art [13]. Contrary to this statement, Montgomery argues that medicine is not a science at all, nor an art. Medicine is a practice where the practitioner must reason not from the general to the particular but from the particular to the general abduction rather than deduction [14]. Furthermore, some researchers believe that a world of rules and expectations is created demanding for all of medicine's questions either to be framed in the language of EBM and judged by its paradigmatic 'gold standard' or be rejected as unimportant [15].

I agree in that EBM is the beginning of trying to get health care providers to unify and standardize their treatment and decision making. But, as well as different beliefs, expectations and social situation of our patients and the fact that not always valid and relevant information exists for the complex context in primary care make it difficult to provide EBM in primary care. Also, experiences, skill level, knowledge of clinicians and patient values and preferences will vary

*Corresponding author: Dr. Tamer Edirne, Department of Family Medicine, Medical School, University of Pamukkale, Denizli, Turkiye; E-mail: tedirne@pau.edu.tr

Received October 04, 2012; Accepted October 06, 2012; Published October 09, 2012

Citation: Edirne T (2012) Is Evidence-Based Medicine Appropriate in Primary Care? Primary Health Care 2:e108. doi:10.4172/2167-1079.1000e108

Copyright: (c) 2012 Edirne T. This is an open-access article distributed under the terms of the Creative Commons Attribution License, which permits unrestricted use, distribution, and reproduction in any medium, provided the original author and source are credited. 
greatly contributing to clinical decisions not based on the best available evidence. What is to be done? Since you can not control everything, at least some systematic guide to provide a starting ground is necessary. First of all, while gathering the most updated information for treatment decisions via EBM, guidelines should take several factors into account, most importantly the family, social, ethnic, policy and legislative issues and limitations and not to forget the subjectivity and values and preferences of clinicians. Greenhalgh suggests that we should need to get out more, and learn from other disciplines especially the social sciences and humanities [16].

In my opinion, to determine which strategy will best serve primary care, results from locally produced mini research summaries and recommendations that address multimorbidity and contextual factors such as family, community and local resources should be evaluated and incorporated into the guidelines.

I agree with Montgomery in that the skilled practice of medicine is not merely about knowing the rules, but about deciding which rule is most relevant. This remains under-acknowledged and under-theorized in the dominant EBM paradigm. Our field of action is primary health care, which favors "the hidden agenda" and quality of care also relies on excellent communication skills and truly informed decision-making. To handle the complexity of medicine without loosing the meaning of complexity of illness in the context of relationships is crucial. Patients' and physicians' feelings and emotions as well as the affection between physician and patient should not be neglected. Evidence-based medicine should help us to present the information, the risks to the patient and outline our treatment options and to be able to go on with saying "Mr. Ahmet, based on this information and our discussions, how do you feel about all of this and what would you wish to do?"

\section{References}

1. Sackett DL, Rosenberg WM, Gray JA, Haynes RB, Richardson WS (1996) Evidence based medicine: what it is and what it isn't. BMJ 312: 71-72.

2. Greenhalgh T, Donald A (2002) Evidence based medicine as a tool for quality improvement. Oxford University Press, Oxford.
3. Kahveci R, Meads C (2009) Is primary care evidence-based in Turkey? A crosssectional survey of 375 primary care physicians. J Evid Based Med 2: 242-251.

4. Al Omari M, Khader Y, Jadallah K, Dauod AS, Al-shdifat AA (2009) Awareness, attitude and practice of evidence-based medicine among primary health care doctors in Jordan. J Eval Clin Pract 15: 1131-1136.

5. Al-Ansary LA, Khoja TA (2002) The place of evidence-based medicine among primary health care physicians in Riyadh region, Saudi Arabia. Family Practice 19: 537-542.

6. Shuval K, Shachak A, Linn S, Brezis M, Reis S (2007) Evaluating primary care doctors' evidence-based medicine skills in a busy clinical setting. J Eval Clin Pract 13: 576-580.

7. Beasley BW, Woolley DC (2002) Evidence-based Medicine Knowledge, Attitudes, and Skills of Community Faculty. J Gen Intern Med 17: 632-639.

8. Davies K (2011) Evidence-based medicine: is the evidence out there for primary care clinicians? Health Info Libr J 28: 285-293.

9. Slowther A, Ford S, Schofield T (2004) Ethics of evidence based medicine in the primary care setting. J Med Ethics 30: 151-155.

10. Vause $J$ (2012) Adherence to evidence-based guidelines is the key to improved health outcomes for general practice patients: YES. J Prim Health Care 4: 156158

11. Mangin D (2012) Adherence to evidence-based guidelines is the key to improved health outcomes for general practice patients: NO. J Prim Health Care 4: 158-160.

12. Parsonson BS (2012) The case for practice-based evidence to support evidence-based practice. J Prim Health Care 4: 98-99.

13. Goodyear-Smith $F$ (2012) What is evidence-based practice and how do we get there? J Prim Health Care 4: 90-91.

14. Montgomery K (2005) How doctors think: clinical judgment and the practice of medicine. Oxford: Oxford University Press.

15. Timmermans S, Berg M (2003) The gold standard: the challenge of evidencebased medicine and standardization in health care. Philadelphia: Temple University Press,.

16. Greenhalgh T (2012) Why do we always end up here? Evidence-based medicine's conceptual cul-de-sacs and some off-road alternative routes. J Prim Health Care 4: 92-97. 